\title{
A tessitura dialógica em Eu me lembro, de Edgard Navarro'
}

Marinyze Prates de Oliveira ${ }^{2}$

1. Uma versão preliminar deste texto foi apresentada no XIV Encontro da Socine, em 2010.

2. A autora é professora do Instituto de Humanidades, Artes e Ciências da UFBA e do Programa Multidisciplinar de Pós-graduação em Cultura e Sociedade. E-mail: mpratesoliveira@terra.com.br 


\title{
Resumo
}

Propõe-se aqui analisar o filme Eu me lembro (2005), de Edgard Navarro, no qual o diretor, em um trabalho de recuperação da memória pessoal e da geração a que pertence, tece uma rede inter textual e polifônica, a partir de apropriações, empréstimos e citações de obras e autores inscritos em territórios expressionais e momentos históricos diversos. Assemelhando-se a uma colcha de retalhos, o filme se apresenta como uma tessitura de elementos apanhados na tradição e corresponde a um exemplo privilegiado da maneira pela qual se dá a produção artística na contemporaneidade.

\section{Palavras-chave}

cinema, Brasil, Edgar Navarro

\begin{abstract}
Here we propose to analyze the film Eu me lembro (2005), by Edgard Navarro, in which the director, in an effort to recover his personal memory and the memory of the generation he belongs to, builds up a polyphonic and intertextual network, through appropriations, loans and quotes of works and authors inscribed on expressive territories and diverse historical moments. Resembling a patchwork quilt, the film unfolds a texture of elements taken from tradition and represents a prime example of how the artistic production takes place in contemporaneity.
\end{abstract}

Key-words

cinema, Brasil, Edgar Navarro 
temáticas

livres

Identificados através de denominações diversas, como apropriações, empréstimos, trocas, reciclagens, citações etc., os intercâmbios de elementos constituem uma prática detectável no âmbito da produção artística de diferentes momentos e locais, abrangendo tanto as formas de expressão longamente consagradas - música, pintura, arquitetura, teatro, literatura - quanto as mais recentes, como é o caso do cinema. No entanto, é na contemporaneidade que tais processos encontram seu terreno mais vasto e fértil, favorecido por fenômenos como a transnacionalização, os fluxos migratórios internacionais e, de modo muito especial, pelas redes planetárias de comunicação e informação, uma vez que a mídia, como nenhuma outra instância social, contribui para a diluição das barreiras geográficas, linguísticas, e sociais. Como lembra Lúcia Santaella, hoje são "muitas as razões para esse fenômeno da hibridização, dentre os quais devem estar incluídas as misturas de materiais, suportes e meios, disponíveis aos artistas e propiciadas pela sobreposição freqüente e sincronização conseqüente das culturas artesanal, industrial-mecânica, industrial-eletrônica e teleinformática" (SANTAELLA, 2008: 135). O fato é que, especificamente no território das artes, as relações dialógicas vêm ocorrendo com tal intensidade que já podem ser consideradas uma forma privilegiada de criação, cujos exemplos são inumeráveis.

Na literatura, vale resgatar alguns casos marcantes, como o de Manuel Bandeira, que, como bem evidenciou Afonso Romano de Sant'Anna, "é um refazedor da tradição" e, nos quatro poemas "À maneira de...", pratica estilos semelhantes aos de Alberto de Oliveira, Olegário Mariano, Augusto Frederico Schmidt e E. E. Cummings (SANT'ANNA, 1991: 61). Após se apropriar de versos de diferentes autores, Bandeira atinge, em seu poema "Antologia", as vias da autoapropriação (ou da intratextualidade), compondo-o a partir da 
justaposição de versos de outros poemas anteriores de sua própria autoria. Mais recentemente, Silviano Santiago, tomando de empréstimo o estilo, as preocupações e a voz de Graciliano Ramos em Memórias do cárcere, faz de Em liberdade uma continuação da obra autobiográfica do escritor alagoano, em um gesto de forte abalo da noção de autoria e propriedade intelectual. Carlos Herculano Lopes, por sua vez, apropria-se do poema "O caso do vestido", de Carlos Drummond de Andrade, e reescreve-o sob a forma de romance, que migra para a tela através da direção do cineasta Paulo Thiago.

Nas artes plásticas, não se pode deixar de lembrar o gesto experimental dos dadaístas, que fizeram da colagem um modo de composição do objeto artístico; a ousada iniciativa dos artistas pop de lançar mão de elementos do universo midiático, para criticá-lo usando seus próprios signos; o empenho obsessivo de artistas como Pablo Picasso e Fernando Botero em reciclar obras do período renascentista. Ao pintor espanhol interessava apropriar-se de pinturas clássicas para, com um gesto subversor, desconstruir alguns dos pilares que sustentaram a representação mimética do mundo, como o uso da perspectiva, responsável pela ilusão de profundidade, que propicia o centramento da percepção. Botero, por sua vez, em seus exercícios de retomada da tradição, visa a patentear a relevância do estilo em detrimento da própria temática, promovendo, com suas figuras volumosas, e em um contexto sócio-histórico diverso, surpreendentes ressignificações das obras matriciais.

Já na área cinematográfica, dentre os inúmeros casos de diálogo com obras procedentes de diversos territórios expressionais, tornaram-se emblemáticas as citações feitas por Jean-Luc Godard em Acossado (1959), que tanto homenageiam os filmes B americanos estrelados notadamente por Humphrey Bogart quanto artistas auratizados como William Faulkner e Renoir. Em Zelig (1983), Woody Allen, por sua vez, toma de empréstimo cenas e personagens históricos, como o Papa e Hitler, com os quais o protagonista de seu filme contracena. Operação curiosa se observa em Nós que aqui estamos por vós esperamos (1998), de 
ano I número |

temáticas

livres
Marcelo Masagão, que também aproxima personagens separados no tempo e no espaço, estabelecendo, assim, um processo de pilhagem em relação ao próprio filme de Woody Allen. Por outro lado, as sorrateiras aparições do diretor Alfred Hitchcock em seus filmes, bem como a furtiva presença de atriz Juliette Binoche em A fraternidade é vermelha (Kieslovski, 1994), após ter sido a protagonista de A liberdade é azul, lançado pelo diretor polonês no ano anterior, não corresponderiam igualmente a manifestações do desejo desses cineastas de manterem um fio dialógico costurando suas obras?

\section{Do "plágio" à homenagem}

Se, até pelo menos o século XIV, a criação artística se efetuava pela via da imitação, a partir do Romantismo o ideal de originalidade e autenticidade levou ao reconhecimento do artista como gênio dotado de um dom divino, conduzindo à valorização da singularidade das obras, que passaram a ser consideradas uma expressão da subjetividade de seus criadores. Consequentemente, a derivação tornou-se sinônimo de inferioridade, desprestígio, fraude, parâmetros que atingiriam o ápice no Modernismo, quando, impulsionadas pela busca incessante do novo e do ineditismo, as vanguardas disseminaram o culto à originalidade, na qual repousaria a "essência” da arte. A autoria, deste modo, autenticada pelo valor da assinatura, elevava-se ao seu patamar máximo, contrariando uma tendência de raízes longínquas, segundo observa Heloísa Buarque de Hollanda:

O que é importante ter em mente é o fato de que as noções de autor e autoria não são nem universais nem atemporais. Qualquer exame das culturas da antiguidade, mostra que os textos épicos, líricos ou dramáticos de então, eram simplesmente postos em circulação sem que se encontre qualquer menção à autoria. É ainda fato notório que, naqueles tempos, a garantia do valor ou da veracidade de um texto era sua antiguidade e não sua autoria (HOLLANDA, 2007: 196).

Ao proclamar, na década de 1960, que "todo texto é um mosaico de outros textos", Julia Kristeva - no rastro das reflexões desenvolvidas por Bakhtin 
sobre o dialogismo - contribuiu significativamente para abalar a ilusão da originalidade, diminuindo, por conseguinte, o peso atribuído à propriedade autoral. Hoje, reconhece-se que as obras de arte, longe de serem detentoras de uma essencialidade que as distancia umas das outras, são na realidade composições híbridas em que se processa um intenso diálogo entre muitas vozes que se enriquecem mutuamente. Por conseguinte, ao se abandonar o compromisso estético com a especificidade e a pureza, promove-se uma enorme expansão das possibilidades criadoras, e a apropriação perdeu o sentido pejorativo de "plágio" ou "roubo intelectual" a que esteve associada em diversas circunstâncias, passando a ser encarada como um modo habitual de produzir-se artisticamente.

No campo das criações audiovisuais, dadas sobretudo as facilidades permitidas pelas novas tecnologias, que vêm gradativamente rompendo as barreiras entre a imaginação e a prática, os processos de transporte e ressignificação de elementos através das técnicas de recortes e colagens ganharam possibilidades praticamente infinitas. Essa migração de signos e elementos artísticos de um território expressional a outro força a diluição de fronteiras, tornando-se tênue a demarcação entre diferentes campos expressionais, linguagens, obras e autores. Esse é o aspecto que me interessa examinar no filme Eu me lembro (2005), de Edgard Navarro, obra que oferece possibilidades extremamente amplas de exploração dos processos de empréstimos, citações, hibridizações e reciclagens de elementos na produção artística contemporânea.

\section{Apropriação e catarse, segundo Edgard Navarro}

Eu me lembro é uma obra de caráter memorialístico, que se detém na recuperação da história do protagonista Guiga, espécie de alter ego do diretor, e duplamente vítima da repressão: por um lado, das normas inflexíveis impostas pelo patriarca da família e, por outro, do clima de tensão e asfixia em que o 
ano | número |

temáticas

livres

país foi imerso a partir da instituição do regime militar em 1964. Ao apreender as memórias individuais do protagonista, o filme de Navarro esforça-se por capturar as lembranças de toda uma geração. Através dos objetos postos em cena, dos modos de falar, das indumentárias e comportamentos, da evocação a fatos históricos como a ditadura militar, o movimento hippie e as experiências com as drogas, vão brotando a cada cena do filme fragmentos que constroem um painel de uma juventude que, nas décadas de 1960/70, sob o peso das muitas transformações por que passava o mundo em seus aspectos sociais, políticos e econômicos, debateu-se entre os dilemas de ter de aceitar as normas vigentes e o sonho de reinventar os modos de vida.

O filme inicia-se por uma série de imagens de arquivo que reproduzem cenas de vidas familiares e cotidianas, muitas das quais foram tomadas de empréstimo a Alexandre Robatto Filho, que ocupa o posto de pioneiro do cinema na Bahia, uma vez que as películas produzidas por Diomedes Gramacho e José Dias da Costa, que o precederam, lamentavelmente não chegaram até nós. Embora já reconhecido pelos curtas e média-metragens realizados anteriormente, dentre os quais se destaca o premiado Superoutro, é sintomático que, ao produzir seu primeiro longa, Edgard Navarro opte por iniciá-lo com imagens tomadas de empréstimo a seus precursores baianos, as quais tanto se assemelham ao primeiros filminhos feitos pelos irmãos Lumière, que capturaram momentos ternos e pueris da vida em família. Por meio dessa estratégia, o diretor presta uma dupla homenagem: aos inventores do cinematógrafo e aos pioneiros do cinema baiano, na figura sobretudo de Alexandre Robato, que acreditou na possibilidade de se produzir cinema na Bahia, contrariando todas as dificuldades conjunturais. Tecendo essa rede polifônica, Navarro constrói uma genealogia de sua produção cinematográfica, inserindo-se em uma espécie de linhagem à qual orgulha-se de pertencer e, em um duplo gesto, inscreve seu próprio nome simultaneamente na história do cinema mundial e na do cinema brasileiro - e, consequentemente, baiano. 


\section{Dialogando com Fellini}

Uma das observações mais frequentes da crítica a respeito de Eu me lembro recai sobre as possíveis analogias entre o filme de Navarro e o Amarcord de Fellini, parentesco sugerido pelo próprio título escolhido pelo diretor baiano, sendo o título de Fellini literalmente traduzível por "eu me recordo". Mas a rede intertextual verificável entre ambas as produções vai muito além. Não há dúvida de que Fellini foi um diretor importantíssimo para a geração a que pertence Edgard Navarro, e este nunca fez segredo de sua admiração pela obra do cineasta italiano.

O diálogo que se estabelece entre Eu me lembro e Amarcord explicita-se por meio da convergência de muitas cenas que ressignificam, no contexto brasileiro - e baiano, mais especificamente - da década de 60, fatos que circunscrevem uma família italiana da década de 1930, a começar pelo regime de força ao qual se encontram submetidos os dois países nesses momentos: o fascismo na Itália e a ditadura militar no Brasil. Sob esse clima, são recuperadas as memórias dos jovens Tita, por Fellini, e Guiga, por Navarro, com ênfase especial na iniciação sexual dos personagens, para os quais o desejo e o próprio corpo são espaços a se desvendar no emaranhado de inseguranças inerentes a esse momento de passagem da fase adolescente para a adulta.

Em certos momentos de Eu me lembro, o espectador familiarizado com o filme de Fellini pode testemunhar um processo de íntimo diálogo entre essas duas obras cinematográficas: na cena da festa junina em que a família de Guiga vive um momento de confraternização; na reconstituição da figura do tio maluco, colecionador de garrafas; no destaque do perfil da mãe terna e compreensiva; ou mesmo nas referências às repressões do desejo sexual pelo poder ubíquo da religião. 
ano I número |

temáticas

livres

Igualmente na maneira como Navarro faz uso dos movimentos de câmera, sem virtuosismos nas tomadas nem abusos no uso de closes ou mesmo da câmera subjetiva, nota-se uma consonância entre a forma como Fellini constrói as imagens de Amarcord e o modo como o diretor baiano configura os elementos de seu primeiro longa-metragem. Produzido após longos anos de espera de uma oportunidade para lançar na tela preocupações já apontadas em seus filmes iniciais, Eu me lembro corresponde, sob diversos aspectos, a uma catarse para uma mente inquieta, impedida de manifestar-se pela censura do regime de força que, durante vinte e um anos, calou as vozes dissidentes no Brasil dominado pelos militares.

Não é casual, portanto, a cena em que Guiga assiste a um filme no cinema e, ao se focalizar a tela, o espectador de Eu me lembro constata que se trata de imagens de Ladrões de bicicleta (1948), de Vittório De Sica, um dos filmes que marcaram o apogeu do movimento que se convencionou denominar de Neorrealismo Italiano. Aos cineastas do Terceiro Mundo, diretores como Rossellini, De Sica e Visconti legaram a alentadora lição de que o cinema pode e deve sobreviver às barreiras político-ideológicas, às dificuldades materiais impostas a sua realização e até mesmo às reações de públicos domesticados por estéticas convencionais, de fácil reconhecimento e assimilação. Ainda hoje, ao assistirmos a Isto não é um filme, de Jafar Panahi - que corresponde a um gesto de resistência do diretor iraniano à condenação pelo regime dos aiatolás a seis anos de prisão e vinte de proibição em exercer sua atividade cinematográfica, sob a alegação de fazer "propaganda contra o estado" constatamos que a mensagem do Neorrealismo continua reverberando no mundo da produção artística, que se nega a vergar-se diante do confisco da liberdade de expressão do pensamento e da sensibilidade individual. O diálogo que Navarro estabelece com cineastas que o precederam é, portanto, ampliado em Eu me lembro, sob forma de homenagem, reconhecimento a um legado cujas consequências longe estão de se esgotar. 
A malha narrativa de Eu me lembro, entretanto, tece-se não apenas por meio da inserção no filme de Navarro de contribuições vindas do cinema, mas também da televisão. Ao incorporar ao filme as vinhetas da tevês Tupi e Aratu; imagens da chegada do homem à Lua; trechos do programa Balança mas não cai; o prefixo do programa Rádio Teatro das Américas e do Reporter Esso, o cineasta reforça a ideia de que os meios de comunicação de massa constituem um forte testemunho da história. Os jingles do creme dental Eucalol, da brilhantina Glostora, de Melhoral, Alka Seltzer, leite em pó Mococa, pílulas Dr. Ross, colírio Moura Brasil, regulador Xavier, talco Ross, sabonete Lifebuoy, sabonete Palmolive, creme dental Kolynos, leite Glória, Varig levam a seu turno o espectador - maduro ou jovem - a constatar que muitos desses produtos e marcas são ecos de um tempo passado, que atestam as rápidas transformações no campo da indústria e do consumo pelas quais o mundo passou nas últimas décadas.

O filme de Navarro, como outros tantos que tratam das décadas de 1960 e 1970 no Brasil, recorre ainda aos empréstimos de materiais para transmitir ao espectador a sensação de insegurança e medo que dominou o período de vigência do regime militar, de tristes lembranças para os cidadãos que viram subtraídas a liberdade individual e a legitimidade das instituições democráticas. A truculência com que a ditadura tratou seus opositores é transmitida ao espectador por meio de fotos impactantes - tomadas de empréstimo ao Arquivo Nacional - das autópsias de Lamarca e de outros guerrilheiros e dos conflitos nas ruas do Rio de Janeiro em 1968, ano de instituição do AI-5, que deu início à fase mais sanguinária do regime.

A própria composição de alguns personagens comprova os processos de hibridização de elementos dos quais o diretor lança mão em seu filme. Créu, por exemplo, a empregada negra cuja vida é integralmente dedicada à família de Guiga, corresponde a uma incontestável fusão da Tia Nastácia do Sítio do picapau amarelo, criada por Monteiro Lobato, com a Mammy de E o vento levou..., 
ano I número |

temáticas

livres

dirigido por Victor Fleming em 1939. Ao narrar o descarte da velha empregada negra, que quando não mais se mostra capaz de servir à família branca é enviada para um asilo - onde morre solitária e esquecida de todos aqueles que a tinham como uma "pessoa quase da família" - Navarro faz uma clara referência à perversa subalternização dos negros no Brasil, até hoje excluídos, em sua grande maioria, dos direitos inerentes à condição cidadã.

Ampliando essa teia de apropriações para além do território midiático, Edgard Navarro vai à literatura, à psicanálise e à filosofia, imprimindo ao conteúdo de seu filme uma densidade que, para além de recuperar as memórias do protagonista, constitui-se em uma reflexão sobre o estar no mundo e enfrentar os dilemas da existência. O conceito freudiano do complexo de Édipo é recriado em Eu me lembro por meio das cenas em que Guiga demonstra fixação na figura materna, seja em criança, quando tenta tocar em seu seio ou entrar sob a saia da mãe para cheirar-lhe o sexo, seja no ódio que sente do pai, quando espreita as humilhações e insultos que ele dirige à esposa na hora de dormir. Ao assim proceder, o cineasta insere-se em uma rede intertextual de raízes longínquas, que remontam à Grécia antiga. Conectando-se com a tragédia Édipo Rei, de Sófocles, Navarro bebe a ideia do enigma da esfinge, reiteradas vezes referido pelos personagens em sua busca do autoconhecimento; faz ressoar em seu filme a obra seiscentista Hamlet, de Shakespeare, cujo protagonista alimenta em relação à mãe um sentimento no mínimo ambíguo; evoca o conceito de complexo de Édipo, cunhado por Freud no século XIX, e dessa forma constrói uma extensa corrente polifônica, que liga passado e presente e, em diferentes temporalidades, tenta desvendar os mistérios que habitam os desejos humanos entre o céu e a terra.

Nietzsche é outra voz que reverbera de forma potente em todo o filme do cineasta baiano. Personagem angustiadamente (ou talvez fosse possível dizer metafisicamente) dividido entre ser apolíneo ou dionisíaco, Guiga se debate entre caminhos opostos: o prazer de curtir a juventude, o sexo, a deriva propiciada 
pelas drogas ou o dever de dedicar-se aos estudos, encontrar uma profissão e dar um rumo à vida, segundo as expectativas alimentadas pela cultura familiar e burguesa. Nietzscheanamente, no entanto, e de maneira bastante sutil, na cena final do filme Navarro introduz a leveza da multiplicidade como opção ao peso dos binarismos platônicos. O lema dicotômico - e tirânico - adotado pelos militares, "Brasil: ame-o ou deixe-o", é então reconfigurado por meio da fala de um dos companheiros hippies de Guiga: "Brasil: ame-o e deixe-o". Desse modo, Navarro anuncia a possibilidade de Guiga tornar-se dionisíaco e apolíneo, escolhendo o caminho da arte - que, no entender do filósofo alemão, existe para que não sejamos aniquilados pela realidade. Como diretor cinematográfico, Guiga/Navarro encontra um meio de conciliar profissão e deleite, razão e emoção, realidade e sonho, lucidez e loucura. Para além, todavia, dessas sutis alusões, a voz do autor de $O$ nascimento da tragédia ecoa de forma mais explícita no filme pela boca do personagem Pablito, místico, enigmático, sedutor, através do qual, em uma operação de ventriloquismo, Edgard Navarro expele seu grito mais visceral, tomado de empréstimo a Zaratustra, para sintetizar o espírito que o conduziu na concepção do filme e que parece guiá-lo nas veredas da vida: "Não acredito em um deus que não sabe dançar".

A própria trilha sonora, assinada por Tuzé de Abreu, reflete a tendência do filme de estruturar-se por meio de fragmentos apanhados em momentos e endereços os mais diversos, que vão do popular ao canônico, do local ao global - para usarmos termos que hoje estão na ordem do dia -, resultando em uma teia riquíssima, que se oferece ao olhar e aos ouvidos do espectador como uma colcha de retalhos. Deste modo, as venturas e desventuras dos personagens são embaladas por cantigas de roda, cantos populares, mantras indianos, pelo hino nacional brasileiro, pela "Rapsódia húngara” de Franz Liszt ou ainda pela "Balada número um" de Chopin. A música "Baby”, de Caetano Veloso, se por um lado potencializa a força das imagens de guerrilheiros trucidados pelo regime militar, por outro associa-se a pastiches de canções 
ano I número 1

temáticas

livres

dos Beatles, ajudando a resgatar a atmosfera artístico-cultural da década de 60, balizada no Brasil pelo Tropicalismo, que oswaldianamente promovia uma hibridização do cafona com o moderno, do brega com o chique, do nacional com o estrangeiro, antecipando uma tendência à diluição de fronteiras hierarquizantes, a qual iria recrudescer na pós-modernidade.

\section{Antropofagia navarriana}

O próprio diretor do filme, de alguma maneira, sugere o processo de devoração que pratica na construção de sua obra, por meio da cena em que Guiga corre pela praia, após deixar o sanatório, gritando aos quatro ventos que "A alegria é a prova dos nove" - frase apanhada do "Manifesto antropófago" de Oswald de Andrade, no qual o autor paulista, antecipando-se à posteridade, afirma sem receios: "Só me interessa o que não é meu" (ANDRADE, 1973: 226). Através de seu filme, Navarro ratifica a ideia de que hoje empréstimos e criação são processos compatíveis, que levam à liberação da energia criativa e desconhecem o medo dos desmascaramentos, fazendo do pluralismo sua forma de atuação. $\mathrm{O}$ ecletismo contemporâneo desafia, portanto, as convenções estéticas marcadas pelo ideal de pureza e integridade, da mesma forma que recusa cada vez mais fortemente os binarismos hierarquizantes que punham em lados opostos o erudito e o popular, o canônico e o massivo.

Aliás, se nos detivermos no exame do conjunto de filmes realizados por Navarro antes de Eu me lembro, constataremos que seu gosto pela apropriação manifesta-se desde muito cedo. Em uma operação intratextual, similar à praticada por Manuel Bandeira em seu poema “Antologia”, o próprio Edgard Navarro faz migrar para o final de Eu me lembro a cena de Alice no país das mil novilhas (1976) - curta-metragem por meio do qual o diretor baiano inaugurou sua incursão no fazer cinematográfico - em que o pai, um senhor baixo, de físico atlético e cabelos brancos, aparece dando cambalhotas. De 
igual maneira, a atmosfera surrealista que o cineasta baiano ensaiou em sua produção precedente, sobretudo a que ele denomina de sua "trilogia freudiana" - Alice no país das mil novilhas, por ele considerado um filme oral; $O$ rei do cagaço (1977), vinculado a uma temática anal; e Exposed (1978), que teria uma dimensão fálica - também é transposta para a parte final de Eu me lembro.

Na visão de Jameson, "os artistas e os escritores do presente não conseguirão mais inventar novos estilos e mundos", pois "todos estes já foram inventados; o número de combinações possíveis é restrito; os estilos mais singulares já foram concebidos" (JAMESON, 1985: 23). Não ter a pretensão de cultivar o ineditismo é um dos aspectos que tornam Edgard Navarro um artista do presente, consciente de que, como tudo já foi feito e já foi dito, resta ao criador reconhecer que hoje, como afirma Walter Moser, "todo o passado da arte se transforma em um repertório de formas, em uma reserva de materiais disponíveis que podem ser reutilizados livremente" (MOSER, 1996: 25). ${ }^{3}$ Através dessa operação, em Eu me lembro Edgard Navarro revolve os depósitos da tradição e de lá traz retalhos que, reciclados, ganham nova vida e se oferecem ao olhar - e à memória - do espectador contemporâneo com força e sentido fecundamente renovados.

3. "Toute le passé de l'art transforme en un répertoire de formes, en une reserve de matériaux disponibles qui peuvent être réutilisés librement" (tradução minha). 


\section{Referências bibliográficas}

ano I número |

temáticas

livres
ANDRADE, Oswald. "Manifesto antropófago". In: TELES, Gilberto Mendonça. Vanguarda européia e modernismo brasileiro: apresentação e crítica dos principais manifestos brasileiros. Petrópolis, RJ: Vozes, 1973. p. 226-232.

BAKHTIN, Mikhail. Problemas da poética de Dostoiévski. Tradução de Paulo Bezerra. Rio de Janeiro: Forense Universitária, 2002.

BANDEIRA, Manuel. "Antologia". In: Poesia completa e prosa. Rio de Janeiro: Companhia José Aguilar Editora, 1974.

FREUD, Sigmund. Obras psicológicas completas. Rio de Janeiro: Imago, 1969.

HOLLANDA, Heloísa Buarque de. "Autoria, autorias". In: NUSSBAUMER, Gisele Marchiori (Org.). Teorias \& políticas da cultura: visões multidisciplinares. Salvador: EDUFBA, 2007. p. 195-204.

JAMESON, F. “Pós-modernidade e sociedade de consumo". In: Novos Estudos CEBRAP, São Paulo, nº 12, p. 16-26, jun. 1985.

LOPES, Carlos Herculano. O vestido. São Paulo: Geração Editorial, 2006.

MOSER, Walter. "Le recyclage culturel" In: DIONNE, Claude et al. Recyclages: économies de l'appropriation culturelle. Montréal: L'Univers des Discours, 1996. p. 23-49.

NIETZSCHE, F. Assim falou Zaratustra. Tradução de Alex Marins. São Paulo: Martin Claret, 1999.

NIETZSCHE, F. O nascimento da tragédia. Tradução de Jaco Guinsburg. São Paulo: Companhia das Letras, 1999.

RAMOS, Graciliano. Memórias do cárcere. Rio de Janeiro: Record, 1989.

SANTAELLA, Lúcia. Culturas e artes do pós-humano: da cultura das mídias à cibercultura. São Paulo: Paulus, 2008.

SANT'ANNA, Afonso Romano de. Paródia, paráfrase \& cia. São Paulo: Ática, 1991. 
SANTIAGO, Silviano. Em liberdade. Rio de Janeiro: Paz e Terra, 1981.

SÓFOCLES. Édipo Rei. Tradução de Jean Melville. São Paulo: Martin Claret, 2005.

\section{Obras audiovisuais}

A LIBERDADE É AZUL. Direção: K. Kieslovski, 1993.

A FRATERNIDADE É VERMELHA. Direção: K. Kieslovski, 1994.

ACOSSADO. Direção: Jean-Luc Godard, 1959.

ALICE NO PAÍS DAS MIL NOVILHAS. Direção: Edgard Navarro, 1976.

AMARCORD. Direção: Federico Fellini, 1973.

EU ME LEMBRO. Direção: Edgard Navarro, 2005.

EXPOSED. Direção: Edgard Navarro, 1978.

ISTO NÃO É UM FILME. Direção: Jafar Panahi, 2011.

NÓS QUE AQUI ESTAMOS POR VÓS ESPERAMOS. Direção: Marcelo Masagão, 1998.

O AMIGO AMERICANO. Direção: Wim Wenders, 1977.

O REI DO CANGAÇO. Direção: Edgard Navarro, 1977.

SUPEROUTRO. Direção: Edgard Navarro, 1989.

ZELIG. Direção: Woody Allen, 1983. 